\title{
An Online Alternative to Alleviate Communication Apprehension
}

\author{
Seyit Ahmet Çapan \\ English Language Teaching Department, Çukurova University \\ Sarıçam, Adana 01330, Turkey \\ Tel: +9-322-338-6084_E-mail: sacapan@cu.edu.tr
}

Received: 02-03-2013

doi:10.7575/aiac.ijalel.v.2n.3p.202
Accepted: 02-04-2013

Published: 01-05-2013

\begin{abstract}
Anxiety is an affective factor commonly associated with one's overall performance in a foreign language. As a component of foreign language anxiety, communication apprehension specifically correlates with successful oral production. A plethora of research (Bailey, Onwuegbuzie \& Daley, 2003; Foss \& Reitzel, 1988) has indicated that high levels of communication apprehension negatively affects one's L2 communication abilities. Thus, this study intends to remedy negative effects of communication apprehension on EFL learners by virtual meetings held through computermediated communication. The participants (N: 18) in this study were selected through purposive sampling. The study employed both quantitative and qualitative techniques. To analyze the data collected, a non-parametric test, Wilcoxon Signed Rank Test, was utilized. The results indicated that computer-mediated communication via voice over IP tools made a significant contribution to alleviate communication apprehension levels in the participants with varying degrees of apprehension levels. The study yielded the most drastic reduction in the high apprehension group, since the participants in this group made a significant progress and ended up with moderate levels of communication apprehension. Also, the participants' self-reports revealed that computer-mediated communication yielded remarkably positive changes in their attitudes towards communicating in the target language. Moreover, the study revealed that computer-mediated communication helped to increase their intercultural awareness. Finally, participants provided a bunch of practical suggestions as possible solutions for reducing communication apprehension.
\end{abstract}

Keywords: apprehension, communication, computer-mediated, attitudes

\section{Introduction}

Communication apprehension (CA) refers to feelings of tension and worry one experiences when s/he is required to speak and listen to a foreign language (FL) in a communicative situation. It basically stems from her/his concern that $\mathrm{s} /$ he may fail communicating in the FL. In FL classrooms, CA occurs when a learner does everything but cannot utter a few words or a sentence in cases like answering a question or talking to the teacher. With this regard, CA is, to some extent, interrelated with the fear of negative evaluation because in the classroom, communication apprehensive learners (CALs) are concerned about the possibility of "being evaluated not only by their peers, but also by their instructor" (Young, 1990, p. 550). Related to this view, much research (Jang, 2001; McCroskey, 1977) has revealed that CA has a sound impact on one's performance in L2 and thus, further steps are required to be taken in order to keep students' CA at a reasonable level.

A factor equally important for achievement in learning, particularly in FL learning, is to keep up with the needs and developments of the current age. Individuals' need and desire to learn languages and their interest in technology have made it inevitable for language practitioners to benefit from opportunities offered by technological instruments. Beginning with the early use of tape recorders and movie projectors, FL education has embraced a number of technological tools including radio, televisions, and computers in order to increase the efficiency of language learning (Guo, 2010). The trend has grown to such an extent that mobile phones, IPods and portable music players have all been used extensively. Conole (2008) asserts that technology is now "at the heart of students' lives" (p. 136). Likewise, their expectations about computer assisted learning are growing "sophisticated in terms of interface, design and functionality" (Rogerson-Revell, 2007, p. 58). As a result, FL learning has witnessed a bloom in the number of computer-assisted programs and tools specifically designated for language learning.

However, there is a dearth of research on the relationship between CA and computer-mediated communication (CMC) despite the considerable use of such communication by language learners today. This paper, therefore, attempts to examine how a vastly used CMC tool, Skype, may affect learners' attitudes towards communicating in an FL. The second goal of this study is to gain insights into possible reactions of the participants to using such tools for the stated purpose. Above all, the present study investigates whether the integration of CMC may have any impact on allaying CA levels in an FL. 
1. To what extent does CMC via voice over IP (Vo-IP) tools affect CA levels in low anxious learners?

2. To what extent does CMC via Vo-IP tools affect CA levels in moderately anxious learners?

3. To what extent does CMC via Vo-IP tools affect CA levels in highly anxious learners?

4. What is the impact of CMC via Vo-IP tools on learners' attitudes towards the target language?

\subsection{Literature Review}

CA is defined as "an individual's level of fear or anxiety associated with real or anticipated communication with one person or persons" (Richmond \& McCroskey, 1998, p. 37). Also called communication anxiety, CA can most generally be described as the overly high levels of fear and anxiety linked to an actual or anticipated communicative event with a single person or a group of people (McCroskey, 1977). CA is rooted in learners' perceptions that they will fail to communicate themselves in the FL thoroughly. In other words, it is not a matter of desire because one may still feel apprehensive in a communicative setting even though s/he has a great appetite for communicating. Accordingly, one's CA levels may show considerable variance depending on the "mode of communication" (Cheng, Horwitz \& Schallert, 1999, p. 421). Several studies (Koch \& Terrell, 1991; Price, 1991) consistently indicate that speaking in an FL is the skill most commonly referred by learners as leading to the highest level of apprehension. Nevertheless, this is not to claim that CA occurs merely because learners are speaking in the FL. Young (1990) maintains that speaking causes high levels of apprehension because it requires "on the spot" and "in front of the class" (p. 551) performance. To clarify, learners do not merely speak in the target language in which they feel naive and incompetent, they also speak in front of others. Therefore, FL learners may suffer higher levels of apprehension in the classroom as they need to perform their speech in front of the teacher and their peers.

However, CA is not a stable phenomenon in itself (Foss \& Reitzel, 1988). Although it is true that CALs feel apprehension and reticence during communication, the level of CA they experience fluctuates throughout an interaction. For instance, whereas some apprehensive learners may report suffering from the highest level of apprehension when they start a conversation, others may find concluding a conversation extremely challenging. Gregersen \& Horwitz (2002) maintain that CALs seldom start a conversation. After the communicative event is set and they get into the mood, one can assume that their level of apprehension will decrease. Furthermore, certain acts such as answering a question during a conversation may provoke higher levels of apprehension. Likewise, the volume of apprehension one experiences differ depending on the content of conversation (Jang, 2001). Chen \& Lee (2011) indicate that apprehensive learners feel at ease when talking about familiar topics (like their family), whereas they exhibit higher levels of apprehension while talking about more challenging issues such as their plans for future. Hence, it is evident that although CA does exist due to various reasons, it is not operating constantly throughout a conversation. It is at those moments of peace that CALs may enjoy the pleasure of communicating in the L2.

Moreover, previous studies (Foss \& Reitzel, 1988; Roach \& Olaniran, 2001) reveal certain characteristics that help to identify individuals with high CA levels. Firstly, CALs have low levels of self-esteem (Foss \& Reitzel, 1988). Several researchers (Bailey, Onwuegbuzie \& Daley, 2003) have observed that CALs tend to withdraw from communicative settings because they think that their FL skills are too poor to succeed. Another feature that could help to identify CALs in language classrooms is linked to their preferred classroom procedures. Such factors as time restrictions, requirements imposed by the curriculum and higher possibility of other learners' volunteering make larger classrooms a preferred setting for CALs. Moreover, much research (Gudykunst, 1998; Roach \& Olaniran, 2001) has indicated that learners' cultural background may have a major impact on their CA levels. In particular, people from Asian countries are more prone to suffer from CA (Kubota, 1999; Truitt, 1995) partly because of some cultural tendencies such as considering talking a hindrance for thinking (Kim, 2002). Additionally, Baker \& MacIntyre (2000) propose that CA may be a strong predictor of one's willingness to communicate, since CALs are likely to avoid participating in interaction through the medium of an FL. Overall, one can deduce that high levels of CA have a debilitating impact on language learning and therefore, negatively affect learners' success in FL learning (Foss \& Reitzel, 1988).

\section{Method}

\subsection{Participants}

This study involved 18 participants, of which 7 were males and 11 were females, from English Language Teaching (ELT) and English Language and Literature (ELL) departments enrolled at two different institutions. The participants were selected through purposive sampling in order to have two homogenous groups. Based on their scores on the Foreign Language Classroom Anxiety Scale (FLCAS), the researcher categorized three participants from each university as highly apprehensive, moderately apprehensive and low apprehensive. Then, the researcher combined the participants with the same apprehension level in the same group so that each group consisted of six participants. Due to confidentiality concerns, the research juxtaposed the participants by pseudonyms like "Student 1, Student 2".

\subsection{Instruments}

For data collection purposes, the study employed three questionnaires and a proficiency test which were all distributed and collected via e-mail. Of these, the FLCAS, Quick Placement Test (QPT) and Background Information Questionnaire (BIQ) were distributed prior to the study whereas the completion questionnaire (CQ) was administered after each pair met eight times. Firstly, the FLCAS (Horwitz, Horwitz \& Cope, 1986) was used to measure the participants' pre- and post-test apprehension levels. The FLCAS comprises 33 items scored on a five-point Likert-type scale. The mean scores in the FLCAS range from 33 to 165 on a continuum extending from "strongly disagree (1)" to 
"strongly agree (5)". A few items (i.e. 2, 5, 8, 11, 14, 18, 22, 28 and 32) need reverse scoring so that a higher score always represents higher levels of apprehension. Though there is no standard principle for scoring (Ganschow \& Sparks, 1996), the study adopted Chu's (2008) suggestion that in the FLCAS, an average below 3 indicates low anxiety, between 3-4 moderate anxiety and above 4 high anxiety. Thus, the participants with an FLCAS score of 65 and below were included in low apprehension group, those with a score between 66-119 in the moderate apprehension group and those receiving 120 and above in high apprehension group. Secondly, a proficiency test, the QPT Version 2, was administered in order to ensure that the paired participants would not have any problems in mutual understanding during the virtual meetings. The QPT Version 2 comprises 60 questions evaluating reading, vocabulary and grammar. The researcher scored " 1 " for correct answers and " 0 " for incorrect answers so that the score a participant could get from the QPT ranged between 1-60 points.

Furthermore, the BIQ consists of 10 questions. It probes into personal data including the participants' age, gender, country of birth, and their mother tongue. The BIQ specifically reveals about the participants' age to begin learning English, their reasons for majoring in English, their perceptions about their current proficiency and apprehension levels in English as well as the most apprehension-provoking skill for them. Finally, the CQ comprises seven open-ended questions drilling into the participants' opinions about their experiences with CMC provided in this study. In the form of self-reports, the CQ asks the participants about the differences they perceive between communication in the virtual meetings and traditional classrooms, advantages/ disadvantages of $\mathrm{CMC}$, and possible suggestions to reduce apprehension levels linked to communication in an FL.

\subsection{Procedures and Data Analysis}

The participants had a total of eight virtual meetings with a partner from the other institution. The meetings were held through a commonly used Vo-IP tool (i.e. Skype) which provides synchronous and asynchronous contact. Skype also offers a virtual face-to-face communication as well as an output log for written communication. This study, however, did not allow written communication because the ultimate goal was to improve students' communication skills by alleviating their apprehension levels linked to communication in the FL. The researcher sent the contents for each meeting the day before the meetings. The reason for giving the topics in advance was to prevent any aggravating impact of uncertainty on the participants' communication performance throughout the meetings.

To analyze the data collected through the FLCAS, this study used the non-parametric Wilcoxon Signed Rank Test. The study employed Wilcoxon test because the number of participants was small, and the data did not show normal distribution. As for the CQ, the participants' responses were analyzed to come up with broad categories describing their apprehension levels throughout the CMC sessions. The themes emerging from the participants' responses to the CQ hinted on some important factors interfering with and/or arising from communication through a Vo-IP tool, which could otherwise have gone unnoticed. These factors will be delineated in line with the research questions in the following session.

\section{Results}

\subsection{To what extent does CMC via Vo-IP tools affect CA levels in low apprehensive learners?}

The analysis of pre- and post-test FLCAS scores of low apprehension group revealed a moderate but meaningful difference $(z=2,207, p<.05)$. When the mean average and sums of the FLCAS scores were taken into account, the findings showed that the difference was negatively ranked (See Table 1). That is the participants in the low apprehension group were at the high end of low apprehension with an average of 64 out of 65 before the meetings. However, their apprehension level declined to 59 on average after they were through the meetings, which was attributed to the opportunity provided by the CMC sessions for practicing in the target language. Hence, the differences in the preand post-test FLCAS scores indicate that CA levels of the participants in low apprehension group have benefitted from CMC via Vo-IP tools.

Table 1. Wilcoxon Analysis Results of Low Apprehension Group

\begin{tabular}{cccccc}
\hline Pre- test and Post-test & N & Mean Rank & Sum of Ranks & Z & p \\
\hline Negative Ranks & 6 & 3,50 & 21,00 & 2,207 &, 027 \\
Positive Ranks & 0 &, 00 &, 00 & & \\
Ties & 0 & - & - & & \\
\hline
\end{tabular}

Although the study observed a moderately positive improvement in CA levels of low apprehension group following the CMC meetings they had with their partners (See Figure 1), some interesting points surfaced from the participants' responses to the CQ. The responses of low apprehension group revealed that making mistakes during a conversation in the FL was not a major concern. That is the participants in this group were recognized to feel comfortable about their mistakes. This cohered with Gregersen's (2003) finding that highly apprehensive learners focused more on the form while low-apprehensive learners paid more attention to the meaning. Moreover, the responses of the participants in low apprehension group revealed that they were not concerned about their performance in L2 compared to their partner. That is the low-apprehensive participants did not make any evaluative judgment about themselves based on their 
partners' performance. However, an interesting finding deduced from the questionnaire was the arousal of "pronunciation/ accent" issue. Unlike the moderate and high apprehension groups, the participants in the low apprehension group stated that in some cases, it was difficult to understand their partner due to the unfamiliar accent.

One of the items (i.e. item 7) in the CQ delved specifically into the participants' advices about how to alleviate CA. The responses of low apprehension group to the item offered invaluable suggestions for allaying high CA levels. The participants suggested that teacher encouragement might be a salient factor in decreasing learners' apprehension levels. This suggestion verified Young's (1991) proposition that teacher attitudes played a remarkable role in learners' apprehension levels. Moreover, the low-apprehensive participants stated that practice, particularly with native speakers, would be a key factor to reduce CA. An interesting idea to increase the opportunity to practice in the FL came from Student 5 as she claimed that student exchange programs such as Socrates-Erasmus should be made more widespread.

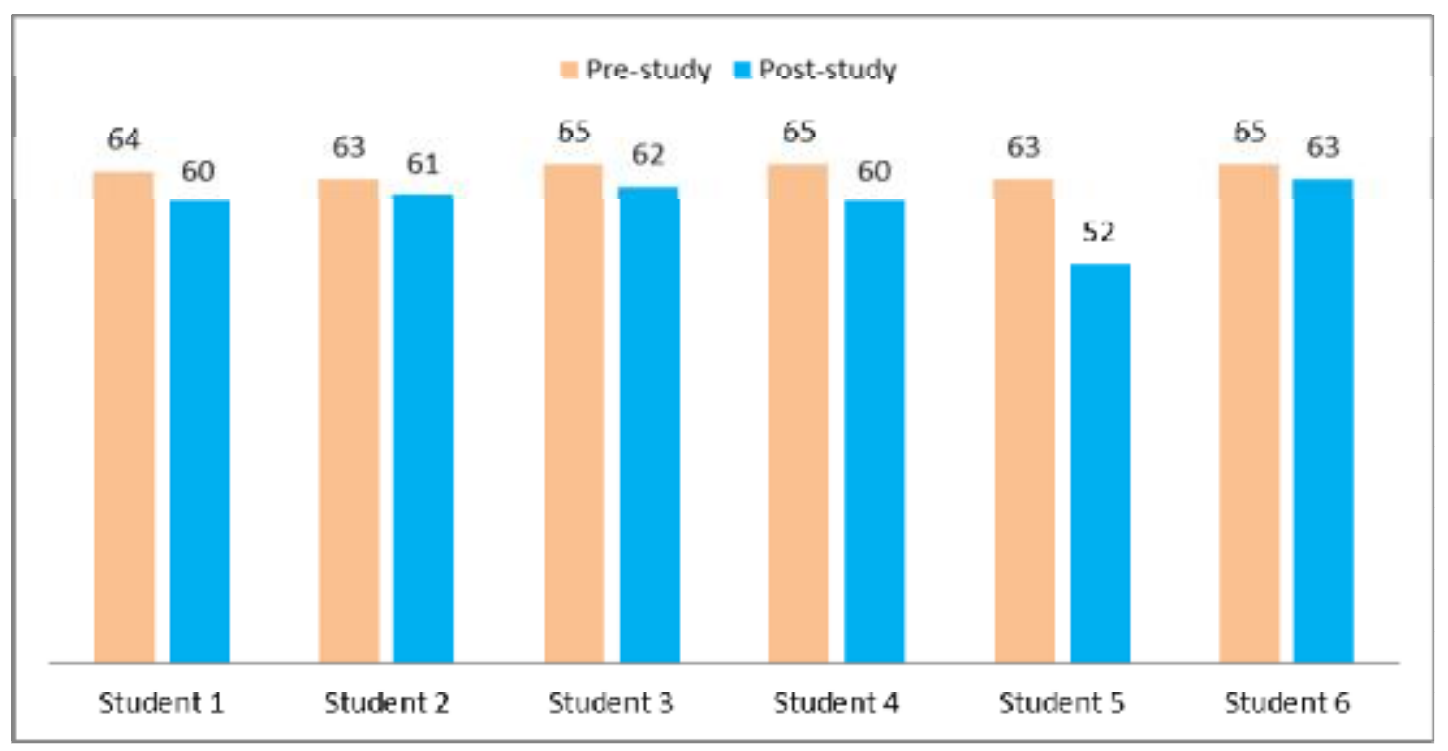

Figure 1. Low apprehension group pre- and post-test FLCAS scores

\subsection{To what extent does CMC via Vo-IP tools affect CA levels in moderately apprehensive learners?}

The Wilcoxon test analysis of the moderate apprehension group highlighted that there was a meaningful difference between pre- and post-test FLCAS scores $(\mathrm{z}=2,201, \mathrm{p}<.05)$ (See Table 2). The study observed a remarkable decrease in the post-test FLCAS results of the moderate apprehension group. The dramatic decrease from an average of 105,5 out of 119 in the pre-test FLCAS scores to an average of 74,5 in the post-test results of the whole group illustrated that the participants in the moderate apprehension group notably benefitted from the CMC meetings. The difference can be better depicted in the individual level. For example, Student 11 previously identified to be at the high end of moderate apprehension levels with an FLCAS score of 110 made a noteworthy progress, and received 74 following the meetings, a score closer to the low end of moderate apprehension levels (See Figure 2). Therefore, this study clearly indicated that $\mathrm{CMC}$ via Vo-IP tools made significant contributions to mitigating CA levels of the moderate anxiety group.

Table 2. Wilcoxon Analysis Results of Moderate Apprehension Group

\begin{tabular}{cccccc}
\hline Pre- test and Post-test & N & Mean Rank & Sum of Ranks & Z & p \\
\hline Negative Ranks & 6 & 3,50 & 21,00 & 2,201 &, 028 \\
Positive Ranks & 0 &, 00 &, 00 & \\
Ties & 0 & - & - & \\
\hline
\end{tabular}

Nevertheless, one should notice that the difference between pre- and post-test FLCAS scores of the moderate apprehension group was not strong enough to label them as "low apprehensive" (See Figure 2). In other words, although there was a salient recovery in their CA levels, it was not significant enough to change their status from moderate apprehension to low apprehension (except for Student 12, who received 59 in the post-test administration of the FLCAS). The controversy that no status change regarding the participants' CA level occurred despite the huge shrink in the post-test FLCAS scores (i.e. from 105,5 in the pre-test to 74,5 in the post-test) should be attributed to the tool used to measure the participants' apprehension levels. As Ganschow \& Sparks (1996) stressed, there were no clearly defined cutoff points for the FLCAS to conclusively distinguish among low, moderate and high apprehension levels. Furthermore, the approximate score range (i.e. 66-119) the researcher used in this study to define the moderate apprehension level might be too broad to yield a sensitive classification. Therefore, the fact that the analysis of the preand post-test FLCAS scores did not represent a change in the moderately apprehensive participants' CA status despite a remarkable decrease revealed a restriction about the FLCAS, which might be compensated by employing a different scale with a more sensitive division of different apprehension levels. 


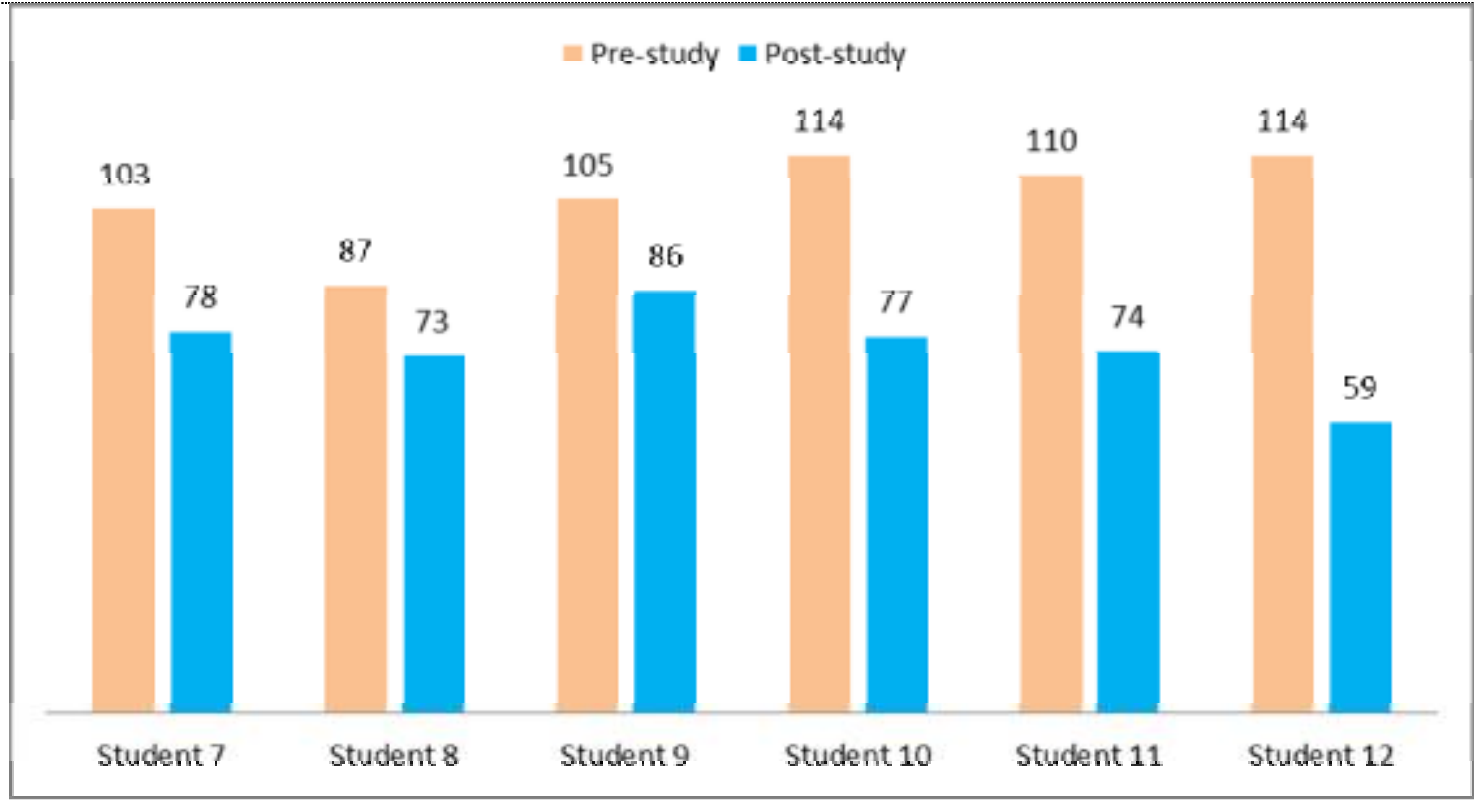

Figure 2. Moderate apprehension group pre- and post-test FLCAS scores

On the other hand, the responses that the moderately apprehensive participants gave to the CQ shed light on some critical points about CA. Firstly, their responses revealed that the moderately apprehensive participants differentiated between the classroom environment and the informal environment provided in the virtual communication sessions. They stated that it was easier to speak in the virtual communication sessions, since there was nobody to monitor their speech. This finding verified Price (1991) as she substantiated that the atmosphere in the classroom was a major contributor to one's apprehension level. Moreover, the participants in the moderate apprehension group showed some concern over the content of speaking as some participants stated that some of the topics in the conversations were more challenging than others. This finding replicated Steinberg \& Horwitz's (1986) premise that the content of speaking might affect students' apprehension levels, since some amount of knowledge in the topic to be covered in a conversation could make up for high levels of apprehension. Another interesting point emerging from the responses of the moderate apprehension group was that they seemed to compromise on the importance of watching films, listening to music and chatting with foreign people as suggestions for mitigating high levels of CA. Yet, the most discernible suggestion came from Student 8 as she stated that "make joke if we don't know what to say." Her statement echoed with Kojima's finding (2007) as she asserted that learners made jokes and smiled when they did not know the answer to a question in the language classroom.

\subsection{To what extent does CMC via Vo-IP tools affect CA levels in highly apprehensive learners?}

The analyses of the high apprehension group's FLCAS scores displayed a significant difference between pre- and posttest results $(z=2,207, p<.05)$. Consideration of the mean average and sums of their FLCAS scores revealed that the post-test scores of high apprehension group were considerably lower than the pre-test scores (See Table 3). Indeed, this study observed the biggest difference between pre- and post-test FLCAS scores in the high apprehension group. The average score of the group diminished from 138,1 out of 165 in the first application to 84,3 in the post-test application, which most clearly represented the positive impact of the CMC sessions. Differences on the individual basis also supported the drastic decrease in CA levels of the participants with high apprehension (See Figure 3). The study resulted in a status shift in their CA levels, since all the participants in high apprehension group ended up with moderate apprehension levels. Besides, their progress from high to moderate apprehension levels was expected to make a great contribution to allaying their negative attitudes towards communicating in the FL as Chastain (1975) hypothesized that moderate levels of apprehension might increase learners' motivation and thus, help them achieve higher performance. Similarly, they could better enjoy communicating in the FL because a great deal of research (MacIntyre \& Gardner, 1994; Yashima, 2002) documented that high levels of apprehension might act as a hindrance for proper communication.

Table 3. Wilcoxon Analysis Results of High Apprehension Group

\begin{tabular}{cccccc}
\hline Pre- test and Post-test & N & Mean Rank & Sum of Ranks & Z & p \\
\hline Negative Ranks & 6 & 3,50 & 21,00 & 2,201 &, 028 \\
Positive Ranks & 0 &, 00 &, 00 & & \\
Ties & 0 & - & - & \\
\hline
\end{tabular}

As to their responses to the CQ, a set of precious insights into the internal feelings of highly apprehensive learners were elicited. Almost all the participants in this group reported that in the first few meetings, they were concerned about their performance compared to that of their partner's as they felt their partners were better. In other words, the highly 
apprehensive participants repeatedly stated that they made comparisons between themselves and their partners, and thought that their partners were doing better than they did. The assumptions of highly apprehensive participants about their own performance shed light on the role of competitive behaviors in one's apprehension level. Therefore, the results of the present study were congruent with previous research as several studies (Bailey, 1983) indicated that learners with high apprehension levels tended to make comparisons between themselves and others in terms of their performance in L2, and undermine their performance.

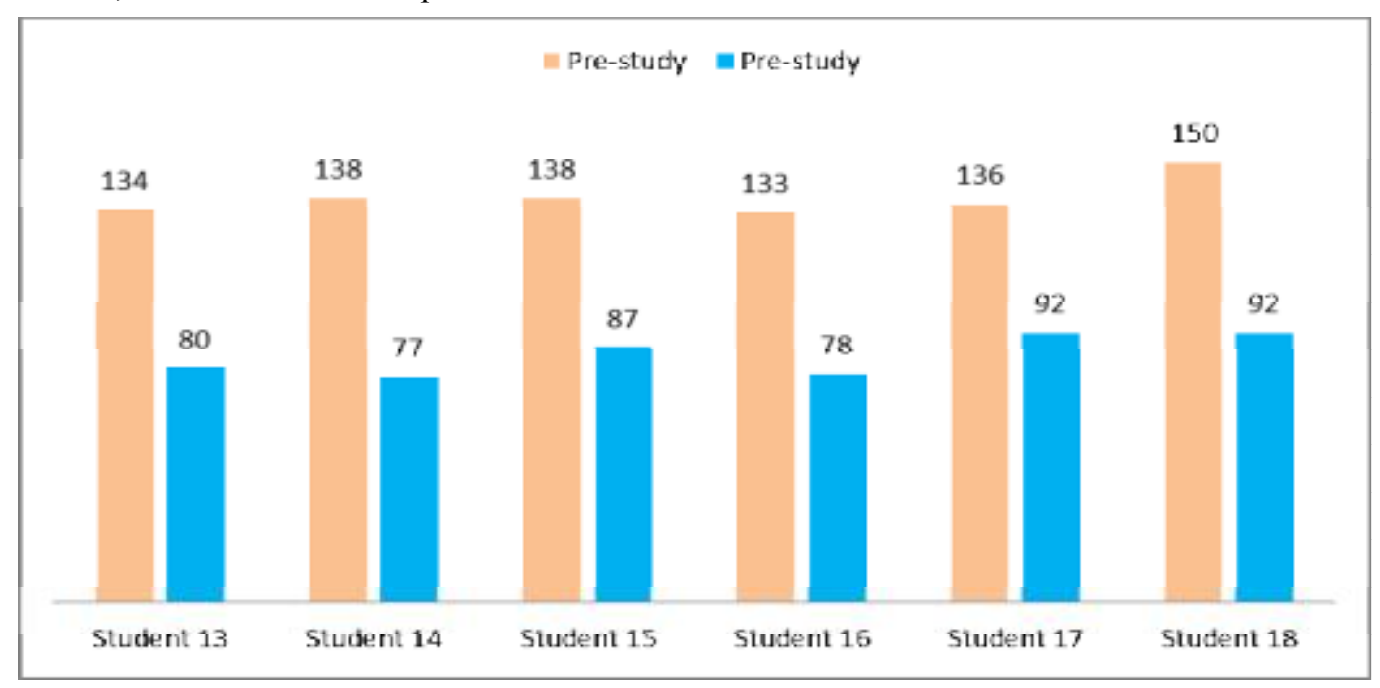

Figure 3. High apprehension group pre- and post-test FLCAS scores

The study pointed out that the highly apprehensive participants had a major concern about making mistakes. Their responses illustrated that the extreme fear attached to making mistakes prevented them from enjoying the pleasure of communicating in the FL. This finding corroborated Horwitz et al.'s (1986) study as they put forth that the fear of making mistake was prevalent in learners with high apprehension. Another interesting corollary of the present study was the implication on the role of the classroom environment in one's CA level. The participants in high apprehension group admitted that the classroom environment increased their apprehension. This added reliability to Koch \& Terrel's (1991) conclusion that the sense of formality in language classrooms might trigger increased levels of apprehension. Finally, the highly apprehensive participants came up with marginal solutions for reducing CA. For instance, Student 16 implied that performing self-talks could be a way of alleviating high apprehension levels as she claimed that "We should speak English opposite to the mirror. I know it is weird but it is beneficial." Also, they suggested that using English outside the classroom would be beneficial in reducing high apprehension levels.

\subsection{What is the impact of CMC via Vo-IP tools on learners' attitudes towards the target language?}

The present study intended to help the participants decrease their CA levels and thereby, enable them to develop positive attitudes towards communicating in the L2. The statistical analyses revealed that the study hit the mark as there was an unequivocal decrease in the posterior FLCAS scores of all participants. Moreover, an analysis of the participants' responses to the CQ revealed major shifts in their opinions before and after the computer-mediated communication meetings, particularly in the moderate and high apprehension groups. The participants in both groups were initially biased against their communicative competence, in particular speaking skill. However, their responses to the questionnaire explicitly indicated that their negative attitudes were incrementally replaced by more positive ones after each virtual meeting. Henceforth, it could be concluded that CMC via Vo-IP tools (such as Skype) provided the participants' with a significant amelioration in their attitudes towards communicating in the target language.

\section{Discussion}

The present study basically attempted to reveal the impacts of CMC on CA levels in FL learners. Analyses of both the FLCAS scores and participants' self-reports provided important insights about CA levels of the participants in each group including interesting guidelines to remedy their apprehension levels. CMC via Vo-IP tools helped all the participants with different apprehension levels make significant progress as the study observed serious amelioration in their overall CA levels. As previous research (Chastain, 1975; Scovel, 1978) emphasized that moderate apprehension in FL learning contexts was indeed a desired phenomenon, the present study added credence to the use of CMC with a focus on alleviating high levels of CA. Moreover, the fact that there was a decrease in the apprehension levels of all three groups, be it statistically significant or not, leaded to the conclusion that keeping abreast of the developments in educational technologies (such as the use of Vo-IP tools in language classrooms) might considerably help to equip FL instructors with favorable and practical solutions in the classroom. In the same fashion, this study well-established that using CMC via Vo-IP tools in order to decrease students' CA levels brought in various additional profits including:

- more opportunities for the participants to practice the target language in real-life situations,

- increase in the participants' motivation to continue studying the target language as they tasted the language with real-life like topics,

- a remarkable save in precious classroom time in that the virtual meetings were held outside the classroom,

- promotion of intercultural awareness. 
Furthermore, the current study revealed that competitiveness might be a factor distinguishing highly apprehensive learners from low-apprehensive learners. This finding echoed with Price's (1991) study as she suggested that competitive behaviors in the form of comparing oneself to others in the language classroom featured as a major trait of students with high apprehension. Therefore, it may be beneficial to communicate students that in the language classroom, one should work for all rather than for herself/himself because FL learning by nature requires more cooperation than competition.

An interesting corollary of the present study was the observation that the issue of pronunciation in the low apprehension group was incongruent with the literature, since pronunciation was a concern previously associated with highly apprehensive students. Horwitz et al. (1986) reiterated that students with high apprehension were identified with setting unrealistic goals such as perfect pronunciation. However, this study reported that it was low apprehension group asking for native-like pronunciation. The distinct finding in this study might be ascribed to the fact that low-apprehensive participants were at the same time highly proficient in English and thusly, more interested in their pronunciation, whereas the moderately and high-apprehensive participants were still striving to take the risk of producing a few sentences in the virtual communication sessions.

Another salient result of the study was that the participants in moderate and high apprehension groups were found to distinguish between the classroom environment and CMC setting. The participants in both groups reported that they felt much safer in the computer-mediated settings. They stated that the virtual setting made them feel more like talking to a close friend who had a language different from their mother tongue whereas in the classroom, they suffered from the risk that they could be interrupted or despised due to a simple mistake they made. This was in line with Koch \& Terrell (1991) as they concluded that the dynamics of the language classroom had a sound impact on FL learners. In the same vein, Ariza (2004) explicated that a warm and supportive classroom environment helped learners feel less threatened and freer to participate. Hence, this study pointed out that CMC via Vo-IP tools could be an attractive alternative to the traditional classroom setting.

Furthermore, the reflections of the participants with moderate apprehension level yielded an attention-intriguing finding about communicating in the target language. The moderately apprehensive participants reported that their levels of CA were affected by the content of communication. It was realized that difficult topics (such as politics and visa policy between countries) were considered more challenging and thereof, caused escalated levels of CA. This finding confirmed Chen \& Lee's (2011) conclusion that unfamiliar topics promoted higher levels of apprehension. Bearing this in mind, it can be suggested that FL instructors pay close attention to cover topics with which students feel more familiar so that they will create some room in which even highly apprehensive students can volunteer to speak.

With regard to the participants' suggestions to mitigate high CA levels, some commonly cited yet valuable ideas were coined. Firstly, the participants with varying levels of apprehension suggested further practice in L2 as a panacea. Apparently, previous research resonated with this point as Elkhafaifi (2005) contended that providing more chances for practicing target structures proved effective in reducing students' apprehension levels. Closely associated with practicing L2, the participants suggested that performing self-talks such as speaking against the mirror could help to allay high levels of CA. Another imaginative suggestion pointed to the importance of increasing intercultural mobility among learners, since one of the participants enthusiastically stated that benefitting from student-exchange programs like Socrates-Erasmus might be a good chance to reduce apprehension levels linked to communication in L2. Further extension of this suggestion pinpoints the importance of using educational technologies. Indeed, it becomes more important to resort to facilities such as Vo-IP tools in cases where there is only limited opportunity to contact with the target language.

Finally, the participants' suggestions attached paramount importance to the role of the teacher in the classroom. The participants asserted that teacher encouragement might play a crucial role in reducing high levels of CA. They stated that in most cases, teacher was the only source of contact with the target language. Therefore, teacher encouragement could help students to recover from high levels of apprehension. In this respect, the present study replicated Samimy \& Rardin's (1994) claim that continuous support provided by the language teacher might decrease students' apprehension levels in the classroom.

\section{Conclusion}

The main objective of this study was to investigate impacts of CMC on FL learners' overall CA levels. As a result of the virtual communication sessions that the participants held via Skype, the study concluded that incorporating CMC into FL education might yield fairly beneficial results. Particularly in alleviating high levels of CA, this study illustrated that CMC via Vo-IP tools helped learners go a long way. It also suggested that CMC could offer precious opportunities to live up to learners' desire to increase their intercultural awareness in the process of learning an FL. As a further step, this study may be repeated to pursue the apprehension levels of the same participants as they continue their study in the same institutes so that one can examine if there is any change in their apprehension levels and any new issue arises in the following years. Additionally, replicating this study with native speakers of English and through different data collection tools may yield critical points about the impact of different study conditions on the results obtained in this study. As this study is limited to English majors, repeating the study with learners majoring in different areas can also help to endorse the reliability and generalizability of the findings. 


\section{References}

Ariza, E. N. (2004). Torn Between Two Worlds: Overcoming Resistance to Second- Language Learning. The Clearing House, 77(3), 105-107.

Bailey, K. (1983). Competitiveness and anxiety in adult second language learning. In H. W. Seliger \& M. H. Long (Eds.), Classroom oriented research in second language acquisition (pp. 67-102). New York: Newbury House.

Bailey, P., Onwuegbuzie, A. J., \& Daley, C. E. (2003). Foreign language anxiety and student attrition. Academic Exchange Quarterly, 7(2), 304-308.

Baker, S. C. \& MacIntyre, P. D. (2000). The role of gender and immersion in communication and second language orientations. Language Learning, 50(2), 311-341.

Chastain, (1975). Affective and ability factors in second language acquisition. Language Learning, 25(1), $153-161$.

Chen, C. M. \& Lee, T. H. (2011). Emotion recognition and communication for reducing second-language speaking anxiety in a web-based one-to-one synchronous learning environment. British Journal of Educational Technology, 42(3), 417-440.

Cheng, Y., Horwitz, E. K. \& Schallert, D. L. (1999). Language anxiety: Differentiating speaking and listening components. Language Learning, 49(3), 417-446.

Chu, H-N. R. (2008). Shyness and EFL learning in Taiwan: A study of shy and non shy college students' use of strategies, foreign language anxiety, motivation and willingness to communicate. Unpublished doctoral dissertation, The University of Texas, Austin.

Conole, G. (2008). Listening to the learner voice: The ever changing landscape of technology use for language students. $\operatorname{ReCALL}, 20(2), 124-140$.

Elkhafaifi, H. (2005). Listening comprehension and anxiety in the Arabic language classroom. The Modern Language Journal, 89(2), 206-220.

Foss, K. A. \& Reitzell, A. C. (1988). A relational model for managing second language anxiety. TESOL Quarterly, 22(3), 437-454.

Ganschow, L. \& Sparks, R. (1996). Anxiety about foreign language learning among high school women. The Modern Language Journal, 80(2), 199-202.

Gregersen, T. S. (2003). To err is human: A reminder to teachers of language-anxious students. Foreign Language Annals, 36(1), 25-32.

Gregersen, T. \& Horwitz, E. K. (2002). Language learning and perfectionism: Anxious and non-anxious learners' reactions to their own oral performance. The Modern Language Journal, 86(4), 562-570.

Gudykunst, W. B. (1998). Applying anxiety/uncertainty management (AUM) theory to intercultural adjustment training. International Journal of Intercultural Relations, 22(2), 227-250.

Guo, S. (2010). From printing to internet, are we advancing in technological application to language learning?. British Journal of Educational Technology, 41(2), 10-16.

Horwitz, E. K., Horwitz, M. B. \& Cope, J. (1986). Foreign language classroom anxiety. The Modern Language Journal, 70(2), 125-132.

Jang, Y. K. (2001). A study on communication anxiety of elementary school student. Unpublished master's thesis, Graduate School of Korea National University of Education, Chung-Buk, Korea.

Kim, H. S. (2002). We talk, therefore we think? A cultural analysis of the effect of talking on thinking. Journal of Personality and Social Psychology, 83(4), 828-842.

Koch, A. S., \& Terrell, T. D. (1991). Affective reactions of foreign language students to natural approach activities and teaching techniques. In E. K. Horwitz \& D. J. Young (Eds.), Language anxiety: From theory and research to classroom implications (pp. 166-172). Englewood Cliffs, NJ: Prentice Hall.

Kojima, E. (2007). Factors associated with second language anxiety in adolescents from different cultural backgrounds. Unpublished Ph.D. Thesis, The University of Southern California, Los Angeles.

Kubota, R. (1999). Japanese culture constructed by discourses: Implication for applied linguistic research and ELT. TESOL Quarterly, 33(1), 9-35.

MacIntyre, P. D., \& Gardner, R. C. (1994). The subtle effects of language anxiety on cognitive processing in the second language. Language Learning, 44(2), 283-305.

McCroskey, J. C. (1977). Oral communication apprehension: A summary of recent theory and research. Human Communication Research, 4(1), 78-96.

Price, M. L. (1991). The subjective experience of foreign-language anxiety: Interviews with highly anxious students. In E. K. Horwitz \& D. J. Young (Eds.), Language anxiety: From theory and research to classroom implications (pp. 101108). Englewd Cliffs, NJ: Prentice-Hall. 
Roach, K. D. \& Olaniran, B. A. (2001). Intercultural willingness to communicate and communication anxiety in international teaching assistants. Communication Research Reports, 18(1), 26-35.

Richmond, V. P. \& McCroskey, J. C. (1998). Communication: Apprehension, avoidance, and effectiveness (5th ed.). Boston: Allyn and Bacon.

Rogerson-Revell, P. (2007). Directions in e-learning tools and technologies and their relevance to online distance language education. Open Learning, 22(1), 57-74.

Samimy, K. K. \& Rardin, J. P. (1994). Adult language learners' affective reactions to community language learning: A descriptive study. Foreign Language Annals, 27(3), 379-390.

Scovel, T. (1978). The effect of affect on foreign language learning: A review of the anxiety research. Language Learning, 28(1), 129-142.

Steinberg, F. S. \& Horwitz, E. K. (1986). The effect of induced anxiety on the denotative and interpretive content of second language speech. TESOL Quarterly, 20(1), 131-136.

Truitt, S. (1995). Beliefs About Language Learning: A Study of Korean University Students Learning English. Texas Papers in Foreign Language Education, 2(1), 1-15.

Yashima, T. (2002). Willingness to communicate in a second language: The Japanese EFL context. The Modern Language Journal, 86(1), 54-66.

Young, D.J. (1990). An investigation of students' perspectives on anxiety and speaking. Foreign Language Annals, 23(6), 539-553.

Young, D. J. (1991). Creating a low anxiety classroom environment: What does language anxiety research suggest? The Modern Language Journal, 75(4), 426-437. 